\title{
Proposta de protocolo para a retomada das atividades em Escolas de Futebol no Brasil
}

\section{A new protocol for reopening Soccer Schools in Brazil}

\begin{tabular}{l} 
AUTORES \\
\hline Luiz Roberto Rigolin 1 (D) $_{\text {Wagner Luiz do Prado }}$ (D) \\
1 Fity - Gestão de Projetos Esportivos. São Paulo, \\
São Paulo, Brasil. \\
2 Department of Kinesiology. California State \\
University San Bernardino. California, USA. \\
CONTATO \\
\hline Luiz Roberto Rigolin. \\
luizrigolin@fity.com.br \\
Rua Coronel Irineu de Castro, 43 - Sala \\
1302, Jardim Anália Franco. São Paulo, São \\
Paulo, Brasil. \\
CEP: 03333-050. \\
DOI
\end{tabular}

$10.12820 /$ rbafs. $25 \mathrm{e} 0121$

\section{(cc) BY}

Este trabalho está licenciado com uma Licenca Creative Commons - Atribuição 4.0 Internacional.

\begin{abstract}
RESUMO
Após um período de redução das atividades econômicas, o Brasil caminha para progressão das medidas de restrição. O objetivo do presente ensaio foi propor um protocolo para o retorno das atividades das escolas de futebol. Para tal, uma busca de artigos científicos foi realizada nas bases de dados $\mathrm{Pu}-$ bmed (Medline) e Web of Science, no período de 10 de junho a 08 de julho de 2020. Após seleção e análise dos artigos científicos relacionados à temática, bem como das recomendações da Organização Mundial da Saúde (OMS) e outras agências mundiais, relacionamos as características específicas das escolas de futebol e do treinamento específico com o nível de reprodução do vírus. O presente protocolo propõe medidas em diferentes níveis: medidas preventivas essenciais e complementares; estruturais; organizacionais, funcionais e diretamente relacionadas à prática esportiva. Espera-se que o presente protocolo possa ser incorporado à rotina diária de escolas de futebol, adequando-se à especificidade de cada local de prática.
\end{abstract}

Palavras-chave: Coronavírus; Treinamento desportivo; Crianças e adolescentes; Saúde.

\section{ABSTRACT}

Brazil is on it's way to reopen its economy after a period of lockdown, reducing the stay-at-home orders. Protocols have been developed aiming to decrease COVID-19's spread. In this study we propose a reopening protocol for Brazilian Soccer Schools. Scientific data were searched at Pubmed (Medline) and Web of Science database from June, $10^{\text {th }}$ to July, $8^{\text {th }}$, 2020. After the search and analyses of the scientific papers, as well as reports from World Health Organization (WHO), and sports agencies around the world, we carefully relate the specific characteristics of soccer demands, exercise training and levels of virus spread. In the present protocol we propose actions to be taken in different levels, as follows: essential and complementary preventive actions, organizational actions, functional actions and those ones strict related to soccer game. It is expected the incorporation of this protocol on soccer schools' daily routine.

Keywords: Coronavirus; Physical training; Children and adolescents; Health.

\section{Introdução}

A pandemia de Coronavírus (COVID-19) tem influenciado decisivamente a história da humanidade. A COVID-19 se propagou rapidamente por diversos países e causou mudanças drásticas na vida das pessoas ${ }^{1,2}$.

O estresse causado pelo isolamento social e economia em recessão ${ }^{3}$ fez com que trabalhadores e empresários começassem a pressionar as autoridades para a reabertura da economia. Entretanto, para que as atividades econômicas sejam retomadas, será preciso considerar a nova realidade.

Escolas de Futebol fazem parte de um dos setores esportivos que pensa em retomar suas rotinas de trabalho, mas para tal, a comunidade científica e demais agentes envolvidos no processo precisam responder a um questionamento: como as aulas poderão ser retomadas de forma segura? Para responder essa pergunta o presente ensaio teórico visa propor um protocolo para o retorno das atividades das escolas de futebol no Brasil.

\section{Desenvolvimento}

O presente protocolo está alicerçado em dados científicos atuais. Uma busca de estudos foi realizada nas bases de dados Pubmed (Medline) e Web of Science no período de 10 de Junho a 08 de Julho de 2020. Ademais, outros protocolos desenvolvidos em outros países para o retorno as atividades esportivas foram analisa$\operatorname{dos}^{4-6}$. O presente protocolo é fruto de uma profunda reflexão dos autores, ambos professores doutores na área de ciências do esporte e profissionais da área do movimento humano, com ampla experiência academica-cientifica, com foco em crianças e adolescentes, e com atuação na gestão de escolas de futebol.

Após seleção e análise dos artigos relacionados à 
temática aqui discutida e das recomendações da Organização Mundial da Saúde (OMS) sobre as precauções necessárias com eventos esportivos durante a pandemia de COVID-19, tivemos a preocupação em relacionar as características especificas das escolas de futebol e do treinamento, com o nível de reprodução do vírus. Ressalta-se que em boa parte dos protocolos elaborados, independentemente da modalidade esportiva (desenvolvidos por confederações e secretarias municipais), não houve a preocupação com a relação entre o nível de contaminação do vírus e o tipo de atividade permitida, questão que nos apresenta como central ${ }^{7-9}$.

O presente protocolo propõe medidas a serem tomadas em diferentes níveis, a saber: medidas preventivas essenciais e complementares, e, entre as complementares, as estruturais, funcionais e as diretamente relacionadas à prática esportiva. A seguir descreveremos as medidas propostas nesse protocolo para o retorno às atividades em escolas de futebol com segurança.

\section{Medidas preventivas essenciais e complementares}

O futebol é um esporte de alto risco de propagação da COVID-19, em razão da necessidade de proximidade entre alunos para treinos e jogos e em razão da alta intensidade para a realização das ações decisivas (quando gotículas podem ser expelidas em distâncias maiores). Portanto, enquanto não houver uma vacina, várias etapas precisam ser estabelecidas para que as Escolas de Futebol tenham segurança para operarem em situações virtuais e presenciais (Quadro 1).
Quadro 1 - Relação do tipo de atividade com a proliferação da COVID-19

\begin{tabular}{lll}
\hline $\begin{array}{l}\text { Atividades de Escolas de Futebol em } \\
\text { Etapas }\end{array}$ & Proliferação & Segurança \\
\hline $\begin{array}{l}\text { 1- Em casa à distância sem máscara } \\
\text { 2- Em casa à distância com máscara } \\
\text { (para adaptação à próxima etapa) }\end{array}$ & $\mathrm{RO}^{\mathrm{Ia}, \mathrm{b}}>1$ & Super seguro \\
$\begin{array}{l}\text { 3- Na escola, com máscara, quadrante } \\
\text { fixo } 9 \mathrm{~m}^{2} \text { e sem contato }\end{array}$ & $\mathrm{RO}^{\mathrm{III}}<1$ & Super seguro \\
$\begin{array}{l}\text { 4- Na escola, com máscara, quadrante } \\
\text { móvel } 9 \mathrm{~m}^{2} \text { e sem contato }\end{array}$ & $\mathrm{RO}^{\mathrm{IV}}<1$ & Seguro \\
$\begin{array}{l}\text { 5- Na escola, com máscara e alunos } \\
\text { em contato }\end{array}$ & $\mathrm{RO}^{\mathrm{V}}<1$ & Seguro \\
6- Na escola, aula normal & & \\
\hline
\end{tabular}

Adaptado de Hugs et al. ${ }^{5}$

\section{Medidas estruturais}

- Providenciar tapetes com água sanitária para limpeza dos pés na entrada da escola.

- Disponibilizar álcool gel 70\% em diferentes locais da escola para higienização das mãos.

- Disponibilizar álcool líquido 70\% para higienização dos materiais.

- Disponibilizar sabonete líquido nos banheiros.

- Providenciar um medidor de temperatura digital e um oxímetro para medir, respectivamente, a temperatura, e o nível de saturação do oxigênio no sangue dos alunos, professores e funcionários ${ }^{\mathrm{VI}}$.

- Desativar bebedouros.

- Providenciar megafone ou microfone com autofalante para os professores ministrarem aula, porque estarão de máscara e precisarão se manter distantes.

- Providenciar máscaras para que todos os profissio-

I a RO é o nível de contaminação do vírus. Acima de 1 a curva está ascendente. Igual a 1 está estabilizada. Abaixo de 1 a curva está descendente. Em cidades grandes a curva é disponibilizada nos meios de comunicação. Já em pequenas não. Nestes casos é imperativo entrar em contato com a secretaria de saúde da região para se informar a respeito do nível de contaminação da COVID-19. b Nessa etapa (1) é importante reforçar as medidas gerais de proteção: higienização dos pés, lavagem das roupas, uso de álcool gel, uso de máscara, distanciamento social e higienização dos alimentos e embalagens

II Estudos prévios (simulando treinamento em altitude) demonstram que a utilização de máscara dificulta a respiração e altera o desempenho esportivo10,11, além de reduzir a eliminação de $\mathrm{CO}_{2}$. Desta forma, espera-se que alguns alunos não se adaptem ao uso da máscara. Nesses casos o ideal é que a aula permaneça em casa até que o aluno se acostume, ou que até que a vacina seja desenvolvida.

III Para que essa etapa (3) seja iniciada é necessário o monitoramento por um mês, isto é, durante 30 dias a curva não pode ascender, tem que se manter estabilizada com tendência à queda. E se houver uma segunda onda, quando a curva voltará a ascender, voltar à etapa anterior (2).

IV Para o início dessa etapa (4), além da curva estar descendente, não deve haver nenhum caso novo na região em que a escola está situada por pelo menos 30 dias, depois do início da etapa anterior (3). Se houver algum novo caso na região, mesmo que essa etapa tenha começado, voltar à etapa anterior $(3)$.

V Para o início dessa etapa (5), além da curva estar descendente, quase em toque com a abcissa, não deve haver nenhum caso novo na região em que a escola está localizada por pelo menos 30 dias depois do início da etapa anterior. Se houver algum caso novo na região, mesmo que essa etapa tenha começado, voltar à etapa 3 e começar o ciclo de novo.

VI A temperatura máxima tolerada é de 37,8 e o nível de saturação do oxigênio no sangue é de no mínimo 95\% de oxigenação. O oxímetro só deve ser utilizado se a temperatura estiver elevada demais ou se a pessoa apresentar os sintomas da COVID-19. De acordo com dados científicos a temperatura não é um bom parâmetro de análise para crianças, já que os dados demonstraram que menos de $50 \%$ delas apresentam quadro febril. A temperatura deve ser vista com cautela como indicador de COVID-19 para crianças12. 
nais da escola trabalhem protegidos e para alunos que não trouxerem máscara reserva.

- Informações, matrículas e pagamentos devem ser feitos de maneira remota.

- Leitores digitais como catraca, não devem ser utilizados.

- Se possível, providenciar um médico para atendimento emergencial, decorrente de alunos e profissionais com os principais sintomas relacionados à COVID-19: febre, perda de paladar, cansaço, tosse seca, dificuldade respiratória e secreção nasal.

\section{Medidas organizacionais}

- Monitorar as regiões de alto contágio e relacionar com as residências da família do aluno, funcionários e professores.

- Monitorar o contágio da COVID-19 com os pais, pelo WhatsApp: família residente com o aluno, parentes, amigos, colegas de trabalho e vizinhos.

- Alunos que convivem com idosos e pessoas de risco (cardiopatas, diabéticos e obesos) devem optar por aula à distância.

- Alunos com menos de 8 anos de idade devem fazer aula apenas à distância (até a fase 5 - Quadro 1), porque nessa faixa etária crianças têm a tendência a se aglomerar, mesmo que haja um professor para tentar conduzi-las.

- Colocar como diretriz que pais não poderão acompanhar o treino dos filhos, para evitar aglomeração.

- Colocar como diretriz que os pais não poderão ficar aglomerados do lado de fora da escola.

- Evitar que os alunos cheguem todos de uma vez.

- O fluxo de pessoas deve ser unidirecional, para evitar que haja várias zonas de contágio e de necessidade de limpeza constante.

- Tornar obrigatório o distanciamento de dois metros entre todos da escola. Colocar localizadores no chão para delimitar a distância.

- Os alunos devem levar uma máscara reserva para trocar durante o treino, se necessário.

- Colocar como dica o tossir e o espirrar colocando o cotovelo na frente da boca.

- Tornar proibido o cumprimento, abraço e beijo entre todos da escola.

- Tornar obrigatório que os alunos não levem nada para a aula exceto a garrafa de água individual, que deve ficar distante uma da outra.

- Evitar o uso de coletes, porque não podem ser reaproveitados para outros alunos antes de serem lavados.
- Tornar obrigatório que os alunos não troquem de equipamento ou de uniforme entre si.

\section{Medidas funcionais}

- Todos os funcionários da escola devem ser treinados quanto às medidas preventivas, assim como pais e alunos.

- Os banheiros devem ser utilizados apenas por uma pessoa de cada vez.

- Os banheiros devem ser higienizados ao término de cada aula.

- A secretaria deve ser higienizada antes ao final das aulas.

- A sala dos professores deve ser higienizada antes e ao final das aulas.

- Alunos e professores devem higienizar as mãos antes e após as aulas.

- As aulas não devem durar mais do que 45 minutos.

- Os quinze minutos que separam uma aula da outra devem ser utilizados para a higienização do material e do ambiente.

- As bolas devem ser higienizadas a cada aula.

- Evitar o uso de celular durante as aulas.

- Fazer a chamada e ao mesmo tempo perguntar ao aluno sobre possíveis contaminados entre familiares, amigos e vizinhos.

- Não deixar de verificar a máscara dos alunos durante o treinamento. A máscara deve tapar o nariz e a boca e se ficar muito úmida, fazer a troca por outra.

- Não deixe que os alunos toquem as bolas com as mãos (exceto os goleiros que devem estar de luvas específicas e higienizadas).

- Se alguém tocar a bola com as mãos, ambos devem ser higienizados imediatamente.

- Entrar em contato com as autoridades médicas se alguém da escola for contaminado e interromper o treinamento por quatorze dias.

\section{Medidas diretamente relacionadas à prática esportiva}

Levando-se em consideração uma possível dificuldade de respiração dos alunos, quando o treino passar da etapa sem máscara (1), para as com máscara (2 a 5), o volume e a intensidade devem ser diminuídos em relação ao treinamento normal. Essa medida levará a uma melhor adaptação e à prevenção de lesões. $\mathrm{E}$ as aulas presenciais com máscara devem durar no máximo 45 minutos.

Para que as aulas possam ser realizadas em quadrantes de 9 metros quadrados, como sugerido no Quadro 1, nas 
etapas 3 e 4, deve haver no máximo 8 alunos nas quadras de futsal e no máximo 10 alunos nas quadras de futebol society. Ao mesmo tempo, só deve haver 1 professor dentro de quadra para as respectivas quantidades de alunos.

Quando a aula for desenvolvida em quadrantes fixos, etapa 3, o ideal é que cada aluno tenha a sua bola. Quando a aula envolver deslocamento dos alunos e mudança de quadrante, etapa 4, tomar muito cuidado para que as distâncias de 3 metros de um aluno para o outro seja mantida, porque a tendência é que eles percam a noção de espaço e invadam os limites de distanciamento.

Nota: para que os alunos passem a bola uns para outros é importantíssimo que os tênis/chuteiras e as bolas, tenham sido higienizados antes do treinamento. Se esse procedimento não for adotado, cada aluno deve treinar de maneira individualizada, com a sua bola.

\section{Considerações finais}

O presente protocolo, desenvolvido a partir de pesquisas atuais sobre a COVID-19 e demais documentos da OMS e entidades internacionais de saúde, apresenta parâmetros claros, objetivos, seguros e adaptados às Escolas de Futebol.

Diante disso, é essencial que os envolvidos no processo tenham amplo conhecimento das medidas protetivas propostas e que passem por um intenso trabalho de conscientização da importância de observância da aplicação das medidas aqui apresentadas. Ademais, espera-se que o presente protocolo possa ser incorporado à rotina diária de escolas de futebol, adequando-se à especificidade de cada local de prática.

\section{Conflito de interesse}

Os autores declaram não haver conflito de interesses.

\section{Contribuição dos Autores}

Rigolin LR, participou da concepção inicial do estudo, redação e revisão crítica do texto. Prado WL, contribuiu com a redação e revisão crítica do texto.

\section{Referencias}

1. Wang C, Pan R, Wan X, Tan Y,Xu L, Ho CS, et al. Immediate Psychological Responses and Associated Factors during the Initial Stage of the 2019 Coronavirus Disease (COVID-19) Epidemic among the General Population in China. Int J Environ Res Public Health. 2020;17(5):1729.
2. Koo JR, Cook AR, Park M, Sun Y, Sun H, Lim JT, et al. Interventions to mitigate early spread of SARSCoV-2 in Singapore: a modelling study. Lancet Infec Dis. 2020;20(6):678-88.

3. Folha de São Paulo. PIB brasileiro deve cair 5\% em 2020 por coronavírus, diz Banco Mundial. [citado em 2020 jul 08]. Disponível em: https://www1.folha.uol.com.br/ mercado/2020/04/pib-brasileiro-deve-cair-5-em-2020-porcoronavirus-diz-banco-mundial.shtml.

4. Chen P, Mao L, Nassis GP, Harmer P, Ainsworth BE, Li F. Returning Chinese school-aged children and adolescents to physical activity in the wake of COVID-19: Actions and precautions. J Sport Health Science. 2020 Apr 12. Disponível em: https://www.ncbi.nlm.nih.gov/pmc/articles/ PMC7154517/ [Epub ahead of print]

5. Hughes D, Saw R, Perera NKP, Mooney M, Wallett A, Cooke J, et al. The Australian Institute of Sport framework for rebooting sport in a COVID-19 environment. J Sci Med Sport. 2020;23(7):639-63.

6. Streng A, Hartmann K, Armann J, Berner R, Liese JG. [COVID-19 in hospitalized children and adolescents]. Monatsschrift Kinderheilkunde : Organ der Deutschen Gesellschaft fur Kinderheilkunde. 2020:1-12.

7. Pagura J, et al. Guia médico de sugestões protetivas para o retorno às atividades do futebol brasileiro. Confederação Brasileira de Futebol. [citado em 2020 Jul 08]. Disponível em: https://www.cbf.com.br/a-cbf/informes/index/cbf-publicaguia-medico-para-retorno-das-atividades-do-futebol.

8. Mezzadri FS, P. . Recomendações e orientações gerais para o esporte brasileiro frente à COVID-19. Instituto de pesquisa inteligência esportiva. [citado em 08 Julho 2020]. Disponível em:http://wwwinteligenciaesportivaufprbr/site/wp-content/ uploads/2020/06/ESPORTE-X-COVID-19pdf.

9. São Paulo GE. Protocolo para retomada das atividades esportivas no estado de São Paulo, considerando o impacto do covid-19 no esporte, atividades físicas e bem-estar. Governo do Estado de São Paulo. [citado em 2020 Jul 08]. Disponível em: https://wwwcoborgbr/pt/documentos/ download/8412b13a39025.

10. Jaguin AR, Dominy TA, Camic Cl, Wrigth Gleenn, Doberstein S, Jones MT, et all. Acute effects of the elevation training mask on strength performance in recreational weight lifters. J Streng Cond Res. 2018;32(2):482-89.

11. Bellovary BN, King KE, Nunez TP, McCormick JJ, Wells $\mathrm{AD}$, Bourbeau $\mathrm{KC}$, et al. Effects of high-intensity interval training while using a breathing-restrictive mask compared to intermittent hypobaric hypoxia. J Human Sport Sci. 2019;14(4):821-33.

12. Souza TH, Nadal JA, Nogueira RJN, Pereira RM, Brandão MB. Clinical manifestations of children with COVID-19: A systematic review. Pediatr Pulmonol. 2020;55(8):1892-99.

Recebido: $15 / 07 / 2020$ Aprovado: 03/08/2020 